Article

\title{
The Göttingen eResearch Alliance: A Case Study of Developing and Establishing Institutional Support for Research Data Management
}

\author{
Jens Dierkes ${ }^{1,2, *, t}$ and Ulrike Wuttke ${ }^{1,3,4,+}$ \\ 1 Niedersächsische Staats- und Universitätsbibliothek Göttingen, Göttingen 37073, Germany; \\ wuttke@akademieunion-berlin.de or Ulrike.Wuttke@gmx.net \\ 2 Gesellschaft für Wissenschaftliche Datenverarbeitung mbH Göttingen, Göttingen 37077, Germany \\ 3 Union der Deutschen Akademien der Wissenschaften, Berlin 10117, Germany \\ 4 Akademie der Wissenschaften zu Göttingen, Göttingen 37073, Germany \\ * Correspondence: dierkes@sub.uni-goettingen.de; Tel.: +49-551-3919188 \\ + These authors contributed equally to this work.
}

Academic Editors: Constanze Curdt, Christian Willmes, Georg Bareth and Wolfgang Kainz Received: 1 March 2016; Accepted: 14 July 2016; Published: 1 August 2016

\begin{abstract}
The Göttingen eResearch Alliance is presented as a case study for establishing institutional support for research data management within the context of the Göttingen Campus, a particular alliance of several research institutes at Göttingen. The cross-cutting, "horizontal" approach of the Göttingen eResearch Alliance, established by two research-oriented infrastructure providers, a research library and a computing and IT competence center, aims to coordinate Campus-led activities to establish sustainable and innovative services to support all phases of the research data life cycle. In this article, the core activities of the first phase aimed at developing a modular approach to provide support for research data management to researchers will be described. It closes with lessons learned and an outlook on future activities.
\end{abstract}

Keywords: research data management; institutional support; research libraries; computing centers; e-research

\section{Introduction}

The digital transformation is fundamentally changing the way research is done in all fields. On the one hand, researchers are processing and studying more digital data in all research fields, on the other hand, research is increasingly conducted in a networked fashion. The Internet, email, videoconferencing, social media, e-journals, Virtual Research Environments, etc., make it possible to work in large, international, and interdisciplinary teams. The digital transformation of academic research culture poses many challenges concerning the management, protection, preservation and sustainable provision of research data, and the shared use of resources. These challenges can only be solved if all stakeholders, from the individual researchers, to universities, libraries, computing centers, and third-party funders work together. In this sense, we understand the term e-research as the provision and usage of digital tools and data in a collaborative and distributed mode [1]. In Germany educational policy bodies and third-party funders aim to join efforts by giving recommendations $[2,3]$ and guidelines [4] (pp. 21-22), [5,6] on research data management on the national level. The German Wiki Forschungsdaten.org [7] provides up to date information about national and international developments concerning research data management. Currently seven German universities (Bielefeld University, Göttingen University, Heidelberg University, Humboldt-University Berlin, Kiel University, TU Darmstadt, and University of Wuppertal) have an institutional research data management guideline or policy according to a sub site of the above wiki [8]. Given the complexity of achieving sustainable 
research data management, a task that requires not only special disciplinary and interdisciplinary RDM skills, but also extra human and financial resources, and based on the insight that additional requirements concerning research data management should be accompanied by institutional support [9] (p. 51), [10] (pp. 67-68), it is no surprise that most German universities that have already issued research data guidelines are also setting up an institutional support infrastructure though the timeline, state of development, and approach may vary with individual circumstances. In this case study, we will have a closer look at the situation at Göttingen, where the Georg-August-Universität Göttingen (Göttingen University) has officially set up the Göttingen eResearch Alliance [11] (eRA) as a support infrastructure parallel to the issuing of its research data guidelines [12]. In the following, the Göttingen eResearch Alliance-including its service offerings in addition to those supporting research data management as such —will be introduced in general terms. In the remaining sections, the focus will be mainly on its service elements concerning research data management support to faculty, followed by a discussion and prognosis for the further development of the campus infrastructure.

\section{The Göttingen eResearch Alliance}

The Göttingen Campus consists of Göttingen University, the University Medical Center, five Max-Planck-Institutes, the Göttingen Academy of Sciences and Humanities, the German Primate Center, and the German Aerospace Center. Together, they form an alliance with a common governance [13]. The members of this alliance and the local infrastructure providers, the Gesellschaft für wissenschaftliche Datenverarbeitung mbH Göttingen (the computing and IT-competence center of Göttingen University and the Max-Planck-Society, GWDG [14]) and the Göttingen State and University Library (Niedersächsische Staats- und Universitätsbibliothek, SUB [15]), are working in close collaboration to provide solutions and support in the context of e-research activity.

Göttingen University, together with the University Medical Center, is one of the first German universities to release a formal research data policy (Research data policy of the Georg-August University Göttingen (incl. UMG), 1 July 2014) [12] to guide its researchers concerning the management of research data. This policy builds on the University's Principles of Good Scientific Practice [16] and its Open Access Policy [17]. As described by Dierkes and Schmidt [18], this data policy is aligned to the respective national guidelines provided by the German Research Foundation [4-6]. Along with the data policy, the university funds the Göttingen eResearch Alliance with five full-time equivalents of new staff for four years to establish an institutional and centralized infrastructure to support researchers in implementing the policy regarding their regular research practices. Currently, the team of the eRA numbers seven members. Three team members are primarily concerned with data management support, while the others are involved in training, outreach, and service development. This initiative was made possible through the strong support of the university's Presidential Board, especially the Vice President for Infrastructures. The founding members of the eRA are the SUB and the GWDG and the joint project, which started in October 2014, draws on a long and successful history of cooperation between the SUB and the GWDG. These research-oriented infrastructure providers already have years of experience in e-research related projects and activities and had already successfully cooperated in diverse e-research related projects such as Pericles, GFBio, DARIAH-DE, TextGrid, and the Humanities Data Centre. The upshot of this is that the eRA team can access a resource consisting of some 70 e-research specialists based at the GWDG and SUB.

After the initial funding period, the results and achievements of the development project will be evaluated. The Presidential Board, the SUB, and the GWDG will then decide on the details of any long term continuation as an institutional support structure. The project manager and the team are supported by a steering committee, which oversees the overall development (Figure 1). The steering committee consists of the directors and senior staff members of the founding institutions and the project manager (eight members). To promote the embedding of the eRA within the organizational structure of the university and to reflect all major information-infrastructure providers, two of the eight 
members of the steering group are represented by the Research Office and the Institute for Medical Computer Science.

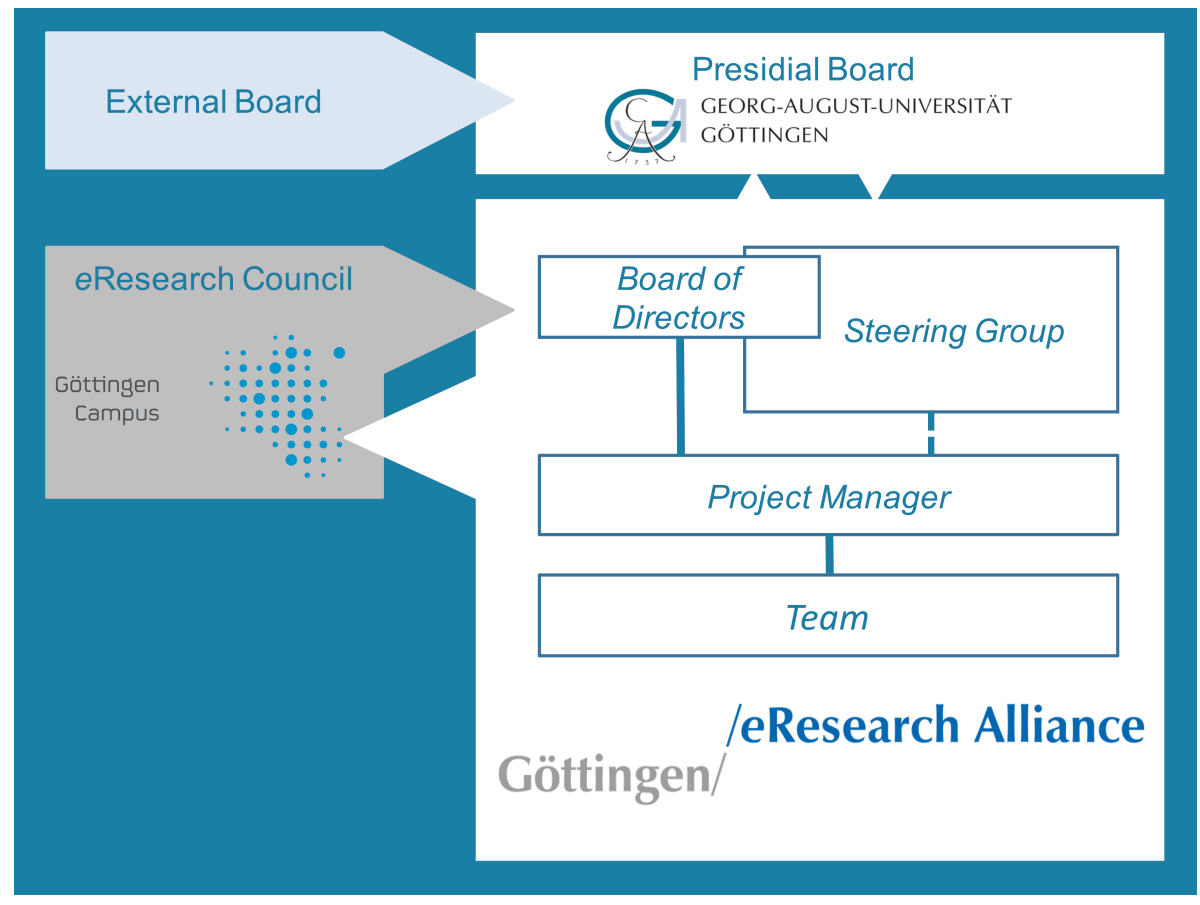

Figure 1. The organizational structure of the Göttingen eResearch Alliance. The steering committee is composed of members of the founding institutions (SUB, GWDG), the university's Research Office, and the Department of Medical Computer Science of the University Medical Centre Göttingen.

A major milestone in the development of a participatory structure was the constitution of the Göttingen eResearch Council in June 2015. The Göttingen eResearch Council is a Campus network of e-research specialists that provides an interdisciplinary platform for strategic discussions of e-research needs and prospective developments between the Göttingen Campus partners and the eRA. Additional to the Göttingen eResearch Council that will meet twice a year, an international External Advisory Board has been established to evaluate and align the eRA activities on the Göttingen Campus with both other national and international developments.

The eRA has made a huge effort during its start-up phase to establish efficient workflows and direct lines of communication, in order to provide individual support to researchers on the Göttingen Campus concerning RDM and other e-research related topics. A crucial element of this consists of strengthening cooperation with the Research Office and other relevant players. We have learned that establishing operational and effective workflows and lines of communication within an extended and complex science hub such as the Göttingen Campus is a complex but critical task. It requires time, patience, diplomatic skills, and subject-specific expertise to bring all stakeholders together. A central component concerning the support of RDM has been the establishment of a workflow to provide subject-specific feedback and assistance on RDM plans for third-party funding proposals, which will be discussed in Section 3.

Though the remainder of this article focuses mainly on the RDM activities of the eRA, the full scope of its mission is considerably broader. It was set up primarily to promote e-research on the Göttingen Campus by building a strong e-research network, and to support researchers to fully exploit the potential of the digital medium for their research throughout the whole research life cycle (cf. [19], p. 43). The eRA supports the research life cycle by offering consultation, training, brokering, and project participation (Figure 2). In particular, the term brokering refers to connecting researchers with existing technical resources, tools and methods, as well as with local experts. Project participation 
refers to collaborative research projects with specific information-infrastructural development needs (cf., Section 3). The website of the eRA [11] plays a central role as an information resource and information hub on e-research for the whole campus. In the following, the focus will be on those measures already introduced concerning RDM support. Based on the experience of the first year of the eRA, insights into how a campus structure for RDM can be further developed and which elements are crucial will be presented.

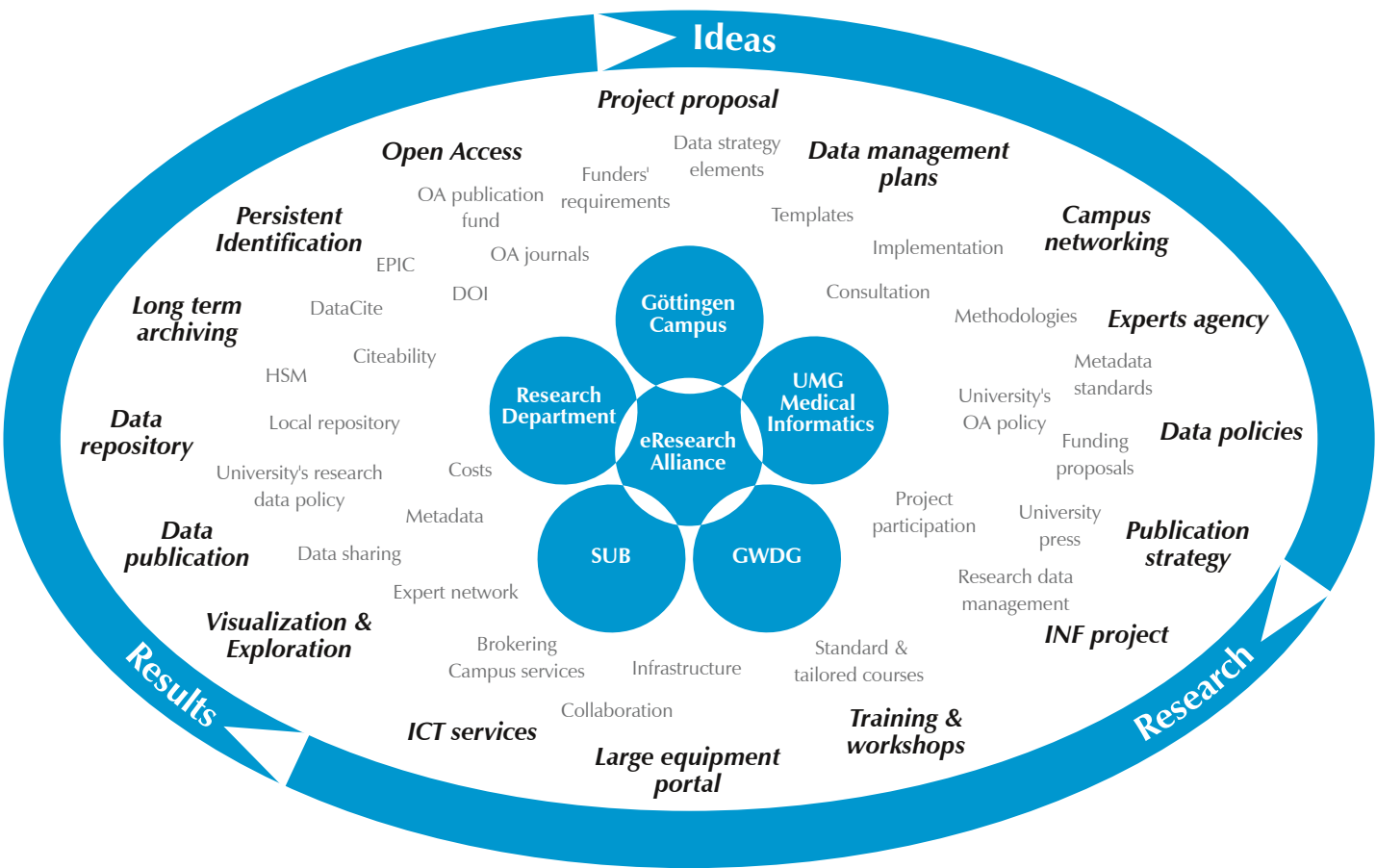

Figure 2. e-Research services along the research life cycle. The terms in bold refer to key e-research topics in the respective research phase. The light grey terms are online service, consulting, training offers by the eResearch Alliance (eRA), by the GWDG, and the SUB. The main task of the eRA is anticipated to be brokering, i.e., connecting researchers to technical resources or experts on Campus.

\section{Data Management Support: Development and Implementation}

Göttingen University has accepted the challenge of the increasing importance of research data in the scholarly communication process and the implications for universities, and has taken the decision to develop and implement a timely set of guidelines for the handling of research data. The research data policy of Göttingen University and specific funders' requirements provide the baseline for the support offered. The preparation and evaluation of a DMP is intended to be a measure of quality assurance. For RDM support to be effective, the central entrance point of contact for RDM consulting is during the grant application phase, during which the eRA can work together with the applicant(s) to develop a data strategy for the bid. In the early stages of the eRA, however, the services were still little known across campus. Larger projects are in any case in contact with the research office, which coordinates the overall application process. The importance of close cooperation with the Research Office is that it helps the eRA-team to become informed about the existence of research projects, as well as ensuring researchers receive information about the offerings of the eRA. This is the principle reason why the university and the eRA have decided to focus on RDM support for larger projects during the start-up phase of the eRA. Gaining intelligence about smaller projects is relatively more challenging. Therefore, the eRA has to actively advertise its services at various levels, such as the faculties and the departments. Another advantage of initially focusing on large projects is that many of the researchers in these consortia are also involved in smaller projects and can act as informal mouthpieces for the 
eRA's services. Due to restricted financial and human resources, however, currently the eRA is only able to provide limited support to ongoing or completed research projects in the form of advice, training, and relatively low-level technology developments. The focus on the application process ensures nonetheless that particular informational technological and expert resources for RDM can be taken into account at an early stage. It also has the advantage that an individual data strategy can be developed together with the researchers which allows for the best possible match between scientific and funders' RDM requirements, which in turn can improve the overall quality of any proposal. In order to provide tailored RDM support regarding the discipline-specific needs of the individual researcher's research project, the eRA team is composed of members of different scientific backgrounds.

\subsection{Consultation for Third-Party Funding Proposals Especially to the German Science Foundation (DFG)}

An important instrument of third-party funding in Germany is that of the large coordinated programs funded by the DFG. These are collaborative research centers (CRCs), research training groups (RTGs) and research units (RUs). Applications for CRCs and RTGs are institutional and the Research Commission of Göttingen University, appointed by the senate of the university, reviews each application before it is submitted to the DFG to ensure that it meets certain quality criteria. Finally, the application is submitted to the DFG on behalf of the university. The overall application process at Göttingen University is coordinated and supported by its Research Office.

As discussed above and because such programs are extremely valuable both in terms of kudos and funding, the eRA provides an evaluation of any bid's data strategy as part of the quality assurance process described above. The evaluation considers the requirements of both the DFG and the Göttingen University data policies and incorporates discipline-specific best practice. As a first step, the eRA had to develop and implement an effective organizational workflow, which involves the researchers, the Research Office, the Research Commission, the eRA, and local IT support.

As part of the workflow, the eRA provides an evaluation concerning the data strategy outlined in a proposal to the research commission. To inform the research commission and the researchers about which RDM aspects are taken into account, the eRA has developed a guide in cooperation with the research commission and the research department (Im Qualitätssicherungsprozess betrachtete Aspekte zu Forschungsdatenmanagement und Publikationsstrategie, currently only available in German, [20]). The main topics addressed are the existence of a data management plan, the degree of usage of local IT and information structure, the clarification of roles and responsibilities within the project, the documentation of data and processes, the consideration of human and technical resources specifically for e-research components, the archiving and accessing strategy for the data beyond the project's life time, and the publication strategy. This workflow is also applied on a smaller scale for DFG proposals for Research Training Groups (RTG) and Research Units (RU). The main focus is on actively and individually supporting and advising researchers on RDM-related issues during the proposal writing process. The quality assurance process is used as leverage for an early consideration of data management issues in an application process.

An important aspect of the workflow outlined above is the concept of a consultant who acts as "a single face to the customer", the researcher(s). It should be noted, however, that in the academic world one should rather think of a partner-ship based cooperation than of a simple provider-client relationship. The consultant is appointed by the project manager of the eRA and selected from among the eRA team and steering committee, depending on the subject area of a proposal as well as its distinctive IT features. She collects the necessary information and requirements related to data management in cooperation with the designated contact person from the research department. In this service-oriented approach, much of the information is gathered 'behind the scenes' and the number of different contacts each researcher has to handle is reduced as much as possible to optimize the effectiveness of the process. Currently, a set of key questions concerning research data management and publication strategy is being developed as a framework during individual consultations and will be made available on the website of the eRA. These questions are based on authoritative sources, 
such as checklists provided by the DCC [21] or the WissGrid-Projekt [22], and refer to the guide for statements provided by the eRA (see above).

In certain cases, the DFG provides support for data management and other e-research related developments within large coordinated research programs. This opens up the opportunity to fund researchers, data managers, and IT-support technical staff. Regarding CRCs, these developments are possible as INF (Information Infrastructure) sub-projects (cf., [23], esp. p. 114). Through such cooperation it is possible to implement sustainable research data management and e-research methods at the center of such large programs. This ensures that relevant issues are addressed during all stages of the research data life cycle and that adequate resources that meet infrastructural needs are planned from the beginning. The concept of embedded data management is relatively new and still evolving. The skills of a data manager appear to be a mixture of those of an IT and research-domain specialist (cf., [24]). Embedded data management seems to offer an appropriate solution for the requirements of large projects with diverse and complex data. It ensures support for the handling of research data along all project phases. The acceptance of the concept of the INF-projects and embedded data managers or data librarians requires a change in research culture, as ideally the data managers are cooperatively embedded into the research projects. Such a departure will require time to become standard research practice (cf. $[23,25]$ ). It is part of the work of the eRA to identify at an early stage needs for project-related infrastructure developments and to support the process for applying for funding. The eRA is also associated to some infrastructure projects. In those projects without a full-scale INF sub-project, or without permanent support positions, the eRA is exploring alternative ways (backed up by the human resources of the two founding institutions, SUB and GWDG) of supporting such researchers, for example by providing a combination of eRA-resource pooling and intense consultation and training.

\subsection{Further Elements of an e-Research Support Infrastructure}

RDM support is not intended to be limited to the application process. Other elements are providing training on data management practices, developing specific technical services for researchers (e.g., for the publication of data), and participating in research projects.

\subsubsection{Face to Face Training's, Online Training, and Information Materials}

The area of RDM training is one of the eRA's fastest growing areas of activity. The eRA provides on-demand training for early career researchers in large coordinated research programs and other institutions on the Göttingen Campus. There are also open workshops for researchers and library staff. RDM training activities vary in length (from $15 \mathrm{~min}$ up to two days) and topics may include RDM basics, Open Data and Open Access basics (in cooperation with the department Electronic Publishing of SUB), and can be in the form of hands-on sessions on the use of specific IT-services available on the Göttingen Campus (e.g., cloud storage, research databases). For the training of early career researchers to be tailored to the specific needs of an individual group, the eRA and the coordinator of the group agree upon the content and format of the training program in advance. If necessary and appropriate, the eRA will call in an expert for a specific topic. It has proven especially fruitful to directly involve the participants into the preparation phase. This can be done, for example, by interviewing volunteers about their current research data practices and their specific needs and expectations, and by actively involving them in the training as presenters of specific use cases. Although this approach seems, as far as our experience goes, to increase the effective reception of training on the part of those attending, their direct involvement is neither always possible nor desired, since it places further demands on their (little or nonexistent) time.

Especially PhD-students connected to large collaborative projects are mostly from very different disciplines. Therefore, it is rather difficult to give specific recommendations concerning tools, formats, and retention periods for data to such multi-disciplinary groups. For these groups, the training focuses on RDM basics in order to raise general awareness of the value of data in the 
research process, the Research Data Policy of Göttingen University and its implications, the handling of data in their research group (if applicable) and the requirements of other funders. This includes the definition of a research data strategy, an overview of the available infrastructure for storing data, documentation, and sharing of data, as well as several related aspects such as backup solutions that are available on the Göttingen Campus, metadata, and licenses. Further possibilities are collaborations with other initiatives and institutions on the campus to tailor discipline specific training, such as for the Humanities (together with DARIAH-DE and TextGrid) or the University Medical Department (together with the Institute for Medical Computer Science and the Institute for Medical Statistics).

Hitherto, groups of young researchers who participated in eRA-trainings came from quite diverse areas such as (agricultural) economics, interdisciplinary statistics, cardiovascular science, and chemistry. The training for chemists was part of a new Information literacy menu for research groups of the Faculties of Chemistry and of Physics [26]. In this context, the eRA will provide on request pre-defined training blocks ranging from 15 up to 90 min on topics such as RDM or IT-services on the Göttingen Campus.

One of the emerging trends is the growing involvement of research libraries in the support and consultation of researchers during the digital research process, i.e., as infrastructure partners or by bringing library employees on a temporary basis as embedded data managers or data librarians into collaborative projects. As a result, there is a need for librarians and library staff to stay up to date with recent developments in this field and to acquire complementary skills as described for example in Engelhardt [23] (esp. pp. 107-108) or Akers et al. [27]. The eRA has started to address this demand by providing two advanced training courses on RDM that are open to all librarians and library staff in cooperation the Service Zentrum Hochschulbibliotheken of the SUB. These courses were well attended by participants from all over Germany, which emphasizes the interest in this topic. These courses also provided the eRA with new insights into the potential for developing user-oriented e-research services and the possible roles for research libraries and computing centers based on their specific competences.

The content of these courses was based on the general RDM basics for PhD students mentioned above, but with more focus on institutional approaches and the potential roles for libraries. Given the very mixed backgrounds of the participants and the diverse development of RDM at German universities and other institutions, it proved very difficult to serve all needs of the participants, especially those already very advanced in the topic. From this experience we learned that there is definitely an audience for a RDM basic course for librarians, but also a need for a specialist discussion forum as well as room for dedicated sessions on institutional RDM support alongside library conferences or other related conferences or workshops.

Besides face-to-face training and slots, the eRA also strives to provide comprehensive training and information materials on e-research through its website [11]. Therefore, over the past year, the content of the eRA-website has been significantly extended. The focus is on providing general information on e-research combined with subject specific examples, local IT and online services and contact with experts. Currently, a database of local research facilities is also under development. Another essential feature of the new website is a news section in blog format. Though this is not a classi training format, an up-to-date blog post on e-research relevant events, services, methods, projects, or researchers can offer the opportunity to provide poignant in-depth information and is a powerful communication channel to reach more researchers and other relevant players on the Göttingen Campus and beyond.

\subsubsection{Participation in Projects}

There is a considerable demand on the Göttingen Campus for small, limited services like adaptations of software systems, the maintenance of websites or wiki platforms, or support for data curation. However, these services are not free of charge, as they require expert human resources. The eRA is currently investigating the possibilities of using resources already available within the SUB and GWDG to meet this demand. Another path currently being tried out is to employ student assistants for tasks which have a potential for wider application on the campus. Additionally, the eRA helps projects in need of more extensive support to draft a proposal, e.g., to the DFG, to apply for funding 
for designing and implementing appropriate solutions. In most cases, such personnel will comprise domain experts. Through such initiatives it might be possible to establish domain-specific "satellites" in the individual faculties. One such example is the embedded data manager as explained above. The eRA is currently associated with two such projects in the environmental and in the physical sciences. In both projects, the data manager is funded by the CRC on a $50 \%$ basis in a position lasting four years. In one case, another $50 \%$ is related to training and consultation services. The two projects differ, in that for the project on environmental research, the data manager is truly embedded into the research workflow. The data manager of the other project is much more concerned with development of software and technical infrastructure, i.e., is more on the traditional support side. Data management in large coordinated programs requires a considerable institutional commitment. The infrastructure, which is developed within such projects, as well as the experience gained, are of great value for the further development of the campus infrastructure in general.

\subsubsection{Publication of Data}

Part of the scientific process is the publication of results. This often happens in textual form, e.g., as a journal article or a monograph. According to the DFG's memorandum on Safeguarding Good Scientific Practice [4] (pp. 21-22) and the DFG's Research Data Guideline [6], the data underlying the publication should be stored or archived for at least ten years at the institution of origin or a trusted repository. It is also desirable to publish the data, thereby simplifying reproducibility and enabling reuse. Data can be archived at the GWDG or at a subject-specific or general purpose data repository (which can be identified for example via the Registry of Research Data Repositories (re3data, [28]). These solutions involve costs and trust in the quality and longevity of the repository service. There are indications that the recommendation to store data for 10 years is an ideal not yet practiced fully by researchers. This is significant in the context of further work indicating that many researchers require even greater longevity of support for their data. For instance, the RMD survey of the Humboldt-University revealed that only $56 \%$ of all respondents keep their data for 10 years or longer ([9], p. 21), leaving a lot of room for improvement on the part of institutional research data service providers to make storing data more straightforward for researchers. Although no local survey concerning RDM has been conducted to estimate the concrete practices at the GC, it can be supposed that the situation is comparable. One of the most promising measures to improve the storage and publication of research data might be the provision of a central local institutional data repository $[9,29,30]$.

In this context, a repository which is maintained by a robust institution with a natural long-term view of information management offers advantages. Universities as enduring institutions can maintain trustworthy archives and repositories and facilitate access to storage solutions with local support. Göttingen University already offers central institutional services for the electronic publications produced by members of the university (GoeScholar, GoeDoc, eDiss, Göttingen University Press). The department of Electronic Publishing of the SUB coordinates these services. A central institutional solution for the associated research data underpinning these publications is still however missing. Therefore, the eRA is currently coordinating the development of a research data repository for the Göttingen Campus. Based on LibreCat, this repository will soon provide a home especially for long-tail research data, for which no subject-specific repository exists. The repository will be connected to the current research information and publication management system of the university, which is currently being upgraded. Additionally, the SUB is developing a service to register Digital Object Identifiers (DOIs) in the humanities subject area in its role, since 2015, as the DataCite member in Germany with a particular focus on the digital humanities, as indicated on the Data Cite Website [31]. This component will be integrated in the local repository to allow the discovery and citation of data, as well as cross references for all disciplines. The eRA will act as a broker for the DOI service on the Göttingen Campus. 


\section{Conclusions and Outlook}

Although most German funders and research policy makers recognize the importance of RDM, there are currently no compulsory RDM policies in place. This might in part be due to the constitutional protection for freedom of scientific research (article 5 of the German Constitution) which makes regulations of the research process a politically sensitive topic. Based on the insight that sustainable RDM will only become (voluntarily) an integral part of the research process if its support is considered as an institutional objective, Göttingen University has instituted a local research data guideline and established the eRA as an appropriate institutional support structure for its implementation. The activities of the eRA are aimed at providing an optimal information infrastructure for research by bundling knowledge about existing IT and information scientific resources, solutions, and experts, and acting as a central point of contact concerning e-research. Joining up the diverse fields of activities, as well as the professional expertise and excellent technical resources of a computing center and a research library is an important step to build comprehensive, coherent, and sustainable institutional support for RDM and fostering data-driven research on the Campus. As part of this effort, the seven-person, multidisciplinary team of the eRA provides general support and training for RDM. An alliance of strong infrastructure partners, such as those represented in the eRA, providing institutional support for RDM and e-research offers great opportunities for promoting such research. When allocating special funds to the development of an e-research infrastructure for the Göttingen Campus, both the library and the computing center have committed themselves to fund permanent positions for e-research tasks after the initial phase (2014-2018). The details of the duties and the job specifications will be subject to an evaluation within the University towards the end of the project phase, taking the recommendations of the External Advisory Board into consideration.

Implementing new communication structures and workflows requires time, since it involves the adaptation of established workflows throughout the Göttingen Campus and the establishment of new lines of contact between the eRA and the individual players on the Campus. The process involves top-down and bottom-up components, such as quality assurance and the articulation of specific requirements by researchers. After having established the RDM quality assurance workflow as part of the internal review process of DFG grant applications, the initial reluctance (due to the top-down approach) is gradually giving way to a more open and cooperative atmosphere during the support process. Among the lessons learned is making young researchers aware of the importance of RDM. They are the vanguards of the digital transformation and of the transformation of individual research cultures and can serve as multipliers in communicating the importance of RDM into the faculties and individual working groups. Since the end of 2014, the eRA has initiated support for about 25 projects of various types (CRC, RTG, and RU) across all disciplines. Currently, considerable efforts are being invested in a consultation process that is based on the evaluation of individual project bids (on the average about one week per project, depending on the complexity of the project and the familiarity of the researchers with the e-research related aspects of their project). However, it is envisaged that in the course of time the expertise that the eRA is gaining in this way will be translated into more generic case studies. These can be used to efficiently scale up this kind of research support to the Campus. Consequently, more attention can then be given to the remaining advanced cases. The eRA will additionally make more generic training courses available via its website, which will provide extensive information on e-research related topics for individual consultation by researchers.

Success of an initiative such as the eRA strongly depends on its acceptance throughout the Campus. In particular, tangible services have to be offered to researchers. There are two levels of engagement involved: (i) the gathering of support from the departments of the central information infrastructure providers, as well as by on-site IT and data-management units; and (ii) the design of products and services that neatly fit into the researchers' workflows. Personal contacts, especially during the build-up phase of the initiative, are extremely important for the dissemination of information. The communication operates in several directions, for example between the eRA and the researchers. While promoting service offerings, the eRA receives feedback and requirements from the researchers regarding 
service development. Communication between the eRA and other players (e.g., central administration) will support developing policies and establishing effective administrative workflows. A further consideration in this context is that, since the eRA currently only has the status of a project, related staff turnover precisely carries the risk of losing contacts and knowledge.

During the last months the eRA has developed a core service portfolio and focuses now on concrete online services for researchers on the Campus (e.g., data repository, research facilities portal, DOI allocation). Still, it is essential to continuously question the demands of the researchers to improve the eRA-services and to identify new needs. This is partly done by analyzing the consultations and training conducted by the eRA and will be elaborated by carrying out expert interviews.

Acknowledgments: The authors kindly thank the anonymous referees for fruitful comments and suggestions. Special thanks go to Mike Mertens (Göttingen University) for additional comments and editing suggestions. The Göttingen eResearch Alliance is a project of the Georg-August University, Göttingen and is run mutually by Niedersächsische Staats- und Universitätsbibliothek Göttingen and Gesellschaft für wissenschaftliche Datenverarbeitung mbH Göttingen.

Author Contributions: Both authors, Jens Dierkes and Ulrike Wuttke, are members of the eRA project, respectively have been members at the time of the writing of this article (UW). As such, they are involved in all aspects of the program of the eRA and are both contributing equally to this article.

Conflicts of Interest: The authors declare no conflict of interest.

\section{References}

1. Meyer, E.T.; Schroeder, R. The world wide web of research and access to knowledge. J. Knowl. Manag. Res. Pract. 2009, 7, 218-233.

2. Hochschulrektorenkonferenz. Management von Forschungsdaten - Eine Zentrale Strategische Herausforderung für Hochschulleitungen, Empfehlung der 16. HRK-Mitgliederversammlung am 13.5.2014. Available online: http://www.hrk.de/uploads/tx_szconvention/HRK_Empfehlung_Forschungsdaten_ 13052014_01.pdf (accessed on 25 January 2016).

3. Hochschulrektorenkonferenz. Wie Hochschulleitungen die Entwicklung des Forschungsdatenmanagements Steuern können. Orientierungspfade, Handlungsoptionen, Szenarien, Empfehlung der 19. HRK-Mitgliederversammlung am 10.11.2015. Available online: http://www.hrk.de/uploads/tx_ szconvention/Empfehlung_Forschungsdatenmanagement_final_Stand_11.11.2015.pdf (accessed on 25 January 2016).

4. DFG. Sicherung Guter Wissenschaftlicher Praxis (Safeguarding Good Scientific Practice), Denkschrift, Ergänzte Auflage. Available online: http://www.dfg.de/download/pdf/dfg_im_profil/reden_ stellungnahmen/download/empfehlung_wiss_praxis_1310.pdf (accessed on 25 January 2016).

5. DFG. Empfehlungen zur Gesicherten Aufbewahrung und Bereitstellung Digitaler Forschungsdaten. 2009. Available online: http://www.dfg.de/download/pdf/foerderung/programme/lis/ua_inf_empfehlungen_ 200901.pdf (accessed on 25 January 2016).

6. DFG. Leitlinien zum Umgang mit Forschungsdaten. 2015. Available online: http://www.dfg.de/ download/pdf/foerderung/antragstellung/forschungsdaten/richtlinien_forschungsdaten.pdf (accessed on 25 January 2016).

7. Forschungsdaten.org. Available online: http://forschungsdaten.org (accessed on 25 January 2016).

8. Forschungsdaten.org/Data Policies. Available online: http://www.forschungsdaten.org/index.php/Data Policies (accessed on 25 January 2016).

9. Kindling, M.; Schirmbacher, P.; Simukovic, E. Forschungsdatenmanagement an Hochschulen: Das Beispiel der Humboldt-Universität zu Berlin. LIBREAS 2013, 23, 43-63.

10. Meyer-Doerpinghaus, U.; Tröger, B. Forschungsdatenmanagement als Herausforderung für Hochschulen und Hochschulbibliotheken. o-bib 2015, 4, 64-72.

11. Göttingen eResearch Alliance Web Page. Available online: http://www.eresearch.uni-goettingen.de/ (accessed on 25 January 2016).

12. Universität Göttingen. Research Data Policy of the Georg-August University Goettingen (incl. UMG). 2014. Available online: https:/ /www.uni-goettingen.de/en/488918.html (accessed on 29 February 2016). 
13. The Göttingen Campus. Available online: http://www.goettingen-campus.de/ (accessed on 25 January 2016).

14. Gesellschaft für Wissenschaftliche Datenverarbeitung MBH. Available online: https://www.gwdg.de (accessed on 25 January 2016).

15. Niedersächsische Staats- und Universitätsbibliothek. Available online: http://www.sub.uni-goettingen.de (accessed on 25 January 2016).

16. Universität Göttingen. Ordnung der Georg-August-Universität Göttingen zur Sicherung Guter Wissenschaftlicher Praxis. 2012. Available online: https://www.uni-goettingen.de/de/ document/download/81b1b7d68c3c204f483bd7b2aad06831.pdf/Ordnung\%20Sicherung\%20guter\% 20wissenschaftlicher\%20Praxis.pdf (accessed on 25 January 2016).

17. Universität Göttingen. Die Open Access Politik der Universität Göttingen. Available online: http://www.sub.uni-goettingen.de/fileadmin/media/texte/informationsversorgung_z/epu/oapolicy_goettingen-edu_de_110211.pdf (accessed on 25 January 2016).

18. Schmidt, B.; Dierkes, J. New alliances for research and teaching support: Establishing the Göttingen eResearch Alliance. Program 2015, 49, 461-474.

19. Luce, R.E. A new value equation challenge: The emergence of eResearch and roles for research libraries. In No Brief Candle, Reconceiving Research Libraries for the 21st Century; Council on Library and Information Resources: Washington, DC, USA, 2008; pp. 42-50.

20. Im Qualitätssicherungsprozess Betrachtete Aspekte $\mathrm{zu}$ Forschungsdatenmanagement und Publikationsstrategie. Available online: http://www.eresearch.uni-goettingen.de/sites/default/ files/StellungnahmeGuide-V2-SenatsFoKo.pdf (accessed on 25 January 2016).

21. Digital Curation Center (DDC). Available online: http://www.dcc.ac.uk/ (accessed on 25 January 2016).

22. Ludwig, J.; Enke, H. Leitfaden zum Forschungsdaten-Management: Handreichungen aus dem WissGrid-Projekt, Glückstadt, Germany, 2013. Available online: http://www.wissgrid.de/publikationen/ Leitfaden_Data-Management-WissGrid.pdf (accessed on 25 January 2016).

23. Engelhardt, C. Forschungsdatenmanagement in DFG-Sonderforschungsbereichen: Teilprojekte Informationsinfrastruktur (INF-Projekte). LIBREAS 2013, 23, 106-130.

24. Cremer, F.; Engelhardt, C.; Neuroth, H. Embedded data manager-Integriertes Forschungsdatenmanagement: Praxis, Perspektiven und Potentiale. Bibl. Forsch. Prax. 2015, 1, 13-31.

25. Schmidt, B.; Ludwig, J. LIBER Case Study: Piloting Research Data Support at the University of Goettingen. 2014. Available online: http://libereurope.eu/wp-content/uploads/2014/07/LIBER-CaseStudy-Goettingen.pdf (accessed on 25 January 2016).

26. Informationskompetenz-Menü für Arbeitsgruppen: Angebote der SUB Göttingen für die Fakultäten Chemie und Physik. Available online: http:/ /www.sub.uni-goettingen.de/fileadmin/media/texte/fachreferate/ fachreferat_chemie_technik/IK-Menue_Chemie_Physik_20151002.pdf (accessed on 25 January 2016).

27. Akers, K.G.; Sferdean F.C.; Nicholls, N.H.; Green, J.A. Building support for research data management: Biographies of eight research universities. Int. J. Digit. Curation 2014, 9, 171-191.

28. Registry of Research Data Repositories (re3data.org). Available online: http://www.re3data.org/ (accessed on 25 January 2016).

29. Tristram, F.; Bamberger, P.; Çayoğlu, U.; Hertzer, J.; Knopp, J.; Kratzke, J.; Rex, J.; Schwabe, F.; Shcherbakov, D.; Svoboda, D.-F.; et al. Öffentlicher Abschlussbericht von bwFDM-Communities 2016. Available online: http://bwfdm.scc.kit.edu/downloads/Abschlussbericht.pdf (accessed on 20 May 2016).

30. Bauer, B.; Ferus, A.; Gorraiz, J.; Gründhammer, V.; Gumpenberger, C.; Maly, N.; Mühlegger, J.; Preza, J.; Sánchez Solís, B.; Schmidt, N.; et al. Forschende und ihre Daten. Ergebnisse Einer Österreichweiten Befragung 2015. Available online: http:/ / phaidra.univie.ac.at/o:407513 (accessed on 20 May 2016).

31. DataCite/Members. Available online: https://www.datacite.org/about-datacite/members/g\%C3\% B6ttingen-state-and-university-library.html (accessed on 25 January 2016).

(C) 2016 by the authors; licensee MDPI, Basel, Switzerland. This article is an open access article distributed under the terms and conditions of the Creative Commons Attribution (CC-BY) license (http://creativecommons.org/licenses/by/4.0/). 